\title{
Climate Change Impact on Wheat Production in the Southern Great Plains of the US Using Downscaled Climate Data
}

\author{
Kundan Dhakal1, Vijaya Gopal Kakani ${ }^{*}$, Evan Linde ${ }^{2}$ \\ ${ }^{1}$ Department of Plant and Soil Sciences, Oklahoma State University, Stillwater, USA \\ ${ }^{2}$ High Performance Computing Center, Oklahoma State University, Stillwater, USA \\ Email: *v.g.kakani@okstate.edu
}

How to cite this paper: Dhakal, K., Kakani, V.G. and Linde, E. (2018) Climate Change Impact on Wheat Production in the Southern Great Plains of the US Using Downscaled Climate Data. Atmospheric and Climate Sciences, 8, 143-162. https://doi.org/10.4236/acs.2018.82011

Received: December 7, 2017

Accepted: April 5, 2018

Published: April 10, 2018

Copyright (c) 2018 by authors and Scientific Research Publishing Inc. This work is licensed under the Creative Commons Attribution International License (CC BY 4.0).

http://creativecommons.org/licenses/by/4.0/

\begin{abstract}
Gradually developing climatic and weather anomalies due to increasing concentration of atmospheric greenhouse gases can pose threat to farmers and resource managers. There is a growing need to quantify the effects of rising temperature and changing climates on crop yield and assess impact at a finer scale so that specific adaptation strategies pertinent to that location can be developed. Our work aims to quantify and evaluate the influence of future climate anomalies on winter wheat (Triticum aestivum L.) yield under the Representative Concentration Pathways 6.0 and 8.5 using downscaled climate projections from different General Circulation Models (GCMs) and their ensemble. Marksim downscaled daily data of maximum (TMax) and minimum (TMin) air temperature, rainfall, and solar radiation (SRAD) from different Coupled Model Intercomparison Project GCMs (CMIP5 GCMs) were used to simulate the wheat yield in water and nitrogen limiting and non-limiting conditions for the future period of 2040-2060. The potential impact of climate changes on winter wheat production across Oklahoma was investigated. Climate change predictions by the downscaled GCMs suggested increase in air temperature and decrease in total annual rainfall. This will be really critical in a rainfed and semi-arid agro-ecological region of Oklahoma. Predicted average wheat yield during 2040-2060 increased under projected climate change, compared with the baseline years 1980-2014. Our results indicate that downscaled GCMs can be applied for climate projection scenarios for future regional crop yield assessment.
\end{abstract}

\section{Keywords}

Wheat, Climate Change, Marksim, GCMs, Downscaling 


\section{Introduction}

Wheat (Triticum aestivum L.) is a primary staple crop worldwide, with a projected global production of $\sim 740$ million metric tons in 2017 [1]. According to the 2017 estimates of the United States Department of Agriculture (USDA), the U.S. ranks fourth in wheat production by country with a projected production of 49.64 million metric tons. The southern Great Plains of the U.S. (Kansas, Oklahoma, and Texas) accounts for $\sim 30 \%$ of the U.S. wheat production, producing 18.8 million metric tons of winter wheat per year from an area of 7.5 million hectares [2]. Achieving sustainable and equitable food security and profitability of crop production in future relies on better understanding of climate and changes in greenhouse gas concentration [3]. In North America, wheat production is expected to decrease or cease in the southern latitudes and geographic shifts in production in the northern latitudes are more likely to occur [4].

Atmospheric $\mathrm{CO}_{2}$ concentrations recorded at Mauna Loa, Hawaii show an increasing trend for $\mathrm{CO}_{2}$. Initially measured at $313 \mathrm{ppm}$, now at the time of writing this paper the atmospheric concentration has crossed $408 \mathrm{ppm}$ (https://www.esrl.noaa.gov/gmd/ccgg/trends/). Increased emissions of anthropogenic greenhouse gases over the last few decades have exacerbated the situation causing increase in temperature and more frequent and severe weather events over larger spatial domain [5]. Climate variability and extremes have multifold consequences and damage the economy as well as natural systems, and could result in pronounced deleterious impacts on food security in less developed regions of the world.

General Circulation Models (GCMs) encompass state of the art knowledge and utilize the most advanced mathematical models currently available representing physical processes of the planet. They are used to understand how the global climate dynamics responds to increasing greenhouse gas concentrations. The GCMs describe the climate on a three-dimensional grid, with a resolution anywhere from $250-600 \mathrm{~km}$. However, there is a mismatch between the temporal and spatial footprint of the GCM data and data required to run process-based crop models [6]. Therefore, in order to reliably assess climate change impact at finer resolution, downscaling is required on relevant meteorological variables. Several downscaling approaches are available, which can be broadly classified into statistical downscaling and dynamic downscaling. Dynamic downscaling method nests regional climate model (RCM) into the GCM to represent a given boundary forcing but are computationally very expensive. Statistical downscaling methods are seen as alternative to dynamic downscaling methods for they use empirical relationships established between large-scale and fine-scale variables using historical data [7].

Several uncertainties limit the predictability of future climate. Therefore, for a better understanding of climate trajectory in future, different sets of Global Circulation Models and Representative Concentration Pathways are explored to obtain a wider range of conditions while assessing the climatic conditions. Inter 
model differences of GCMs are due to the way certain physical processes, responses, and feedbacks are modelled. The Representative Concentration Pathways (RCPs) are four different emission scenarios that provide time-dependent projections of atmospheric greenhouse gas concentrations. Each pathway represents a range of radiative forcing and emission characteristics, for e.g., RCP2. 6 comprises a stringent mitigation scenario, RCP4.5 and RCP6.0 comprise intermediate scenarios, and RCP 8.5 represents a very high greenhouse gas emission scenario (Figure 1). Current and past anthropogenic greenhouse gas emissions along with natural climatic variability are likely to cause an increase in global surface temperature by $3^{\circ} \mathrm{C}-6^{\circ} \mathrm{C}$ for RCP 6.0 and RCP 8.5 by 2100 [8].

Several studies have shown that rising temperatures affect crop production negatively, due to shortened growing season and decreased photosynthate accumulation in plants [9] [10]. In addition, a meta-analytic summary [11] indicated $\mathrm{CO}_{2}$ fertilization effect to be lower than expected on $\mathrm{C} 3$ crops and little to no effect on $\mathrm{C} 4$ crops. In case of wheat, exposure to higher temperature extremes has been linked to accelerated growth, shorter growing season, and reduced yield [12]. Increase in ambient temperature singly or in combination of drought during reproductive and grain-filling phase in wheat, decrease grain yield and the protein content [13] [14]. Since 1980, warming in Bangladesh and India is considered to have reduced wheat yields by approximately $20 \%$ of their average trend [15]. In the Southern Great Plains of the U.S., Oklahoma and Texas have lower and more variable wheat yields than in the rest of the U.S. [16]. Agricultural production in this region has always been challenged by climate. The situation gets exacerbated due to frequent drought as evapotranspiration exceeds the amount of rainfall. In addition, over the years the ratio of harvest-to-planted ratios in this region is also declining as the wheat fields get abandoned after being used as pasture because part of the crop used as pasture turn out to be more profitable than growing the crop for grain [16]. Since wheat is vital for the southern Great Plains of the U.S. for its impact on the local economy and food

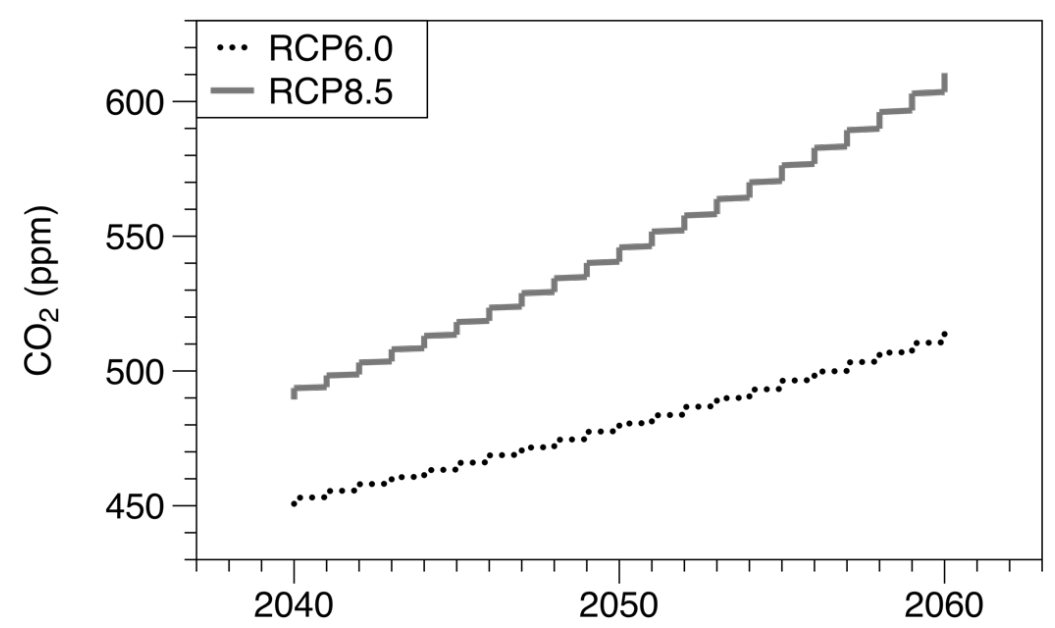

Figure 1. Atmospheric $\mathrm{CO}_{2}$ concentration for RCP6.0 and RCP8.5, source: (Meinshausen et al., 2011). 
security, it is imperative that we understand the effect of changing climate on wheat yield.

Crop simulation models may prove to be a better tool in linking bio-physical drivers of crop production with climate variability. Crop modeling offers a big advantage as various treatments can be investigated in greater detail without actually having to run the experiment on the field, which can be both time and cost prohibitive. Process-based crop simulation models, e.g. [17] [18] [19] [20] are the suitable tools to examine impacts of climate change because of their ability to simulate and mechanistically describe the detailed influences of a wide array of weather variables, plant genotypes, environmental and edaphic factors, management practices, etc. on crop physiological and growth processes. Therefore, these crop simulation models can be very useful in understanding complex and non-linear effects of climate change on crop growth and physiological response.

Previous studies on climate change impacts on wheat production in Oklahoma [21] [22] have been carried out using the IPCC Third Assessment Report Special Report on Emissions Scenarios data of 2000. No literature has been published yet for climate change impact assessment on wheat yield performance using the downscaled AR5 data for this region. Therefore, the objectives of this study were i) to simulate wheat yield under different future climate anomalies at a finer scale over wheat growing areas in Oklahoma using the latest CMIP5 GCM climate projection, and ii) to investigate how wheat yield responds to different climate scenarios for different emission pathways across landscapes of Oklahoma.

\section{Materials and Methods}

\subsection{Study Area}

The study area is Mesonet locations in Oklahoma (Figure 2). Wheat yield was simulated with Decision Support System for Agrotechnology Transfer (DSSAT)Crop Environment Resource Synthesis (CERES)-Wheat v4.6 [23] water and nitrogen limitations $\left(\mathrm{Y}_{w f}\right)$, water limitation $\left(\mathrm{Y}_{\mathrm{a}}\right)$, and no limitations $\left(\mathrm{Y}_{p}\right)$. The sowing date of October 16 (DOY 289) was used for entire simulation. A very popular hard red winter wheat cultivar Duster, developed by the Oklahoma State University Wheat Improvement Team [24] was used in the simulations. Duster performs well in both grain-only and dual-purpose (grazing and grain or hay production). A total of 77 active Mesonet sites were chosen with least missing weather data. The time slices of 1980-2014 and 2040-2060 were selected to represent the baseline and future climate respectively.

\subsection{Crop Simulation Model}

For wheat yield simulation, we used the well-established DSSAT-CERES-Wheat model [18] [25] [26]. DSSAT is a mechanistic simulation model that uses daily weather data, geographical coordinates, sowing date, fertilizer applications and soil properties to predict the growth, development, physiology and yield of crop 


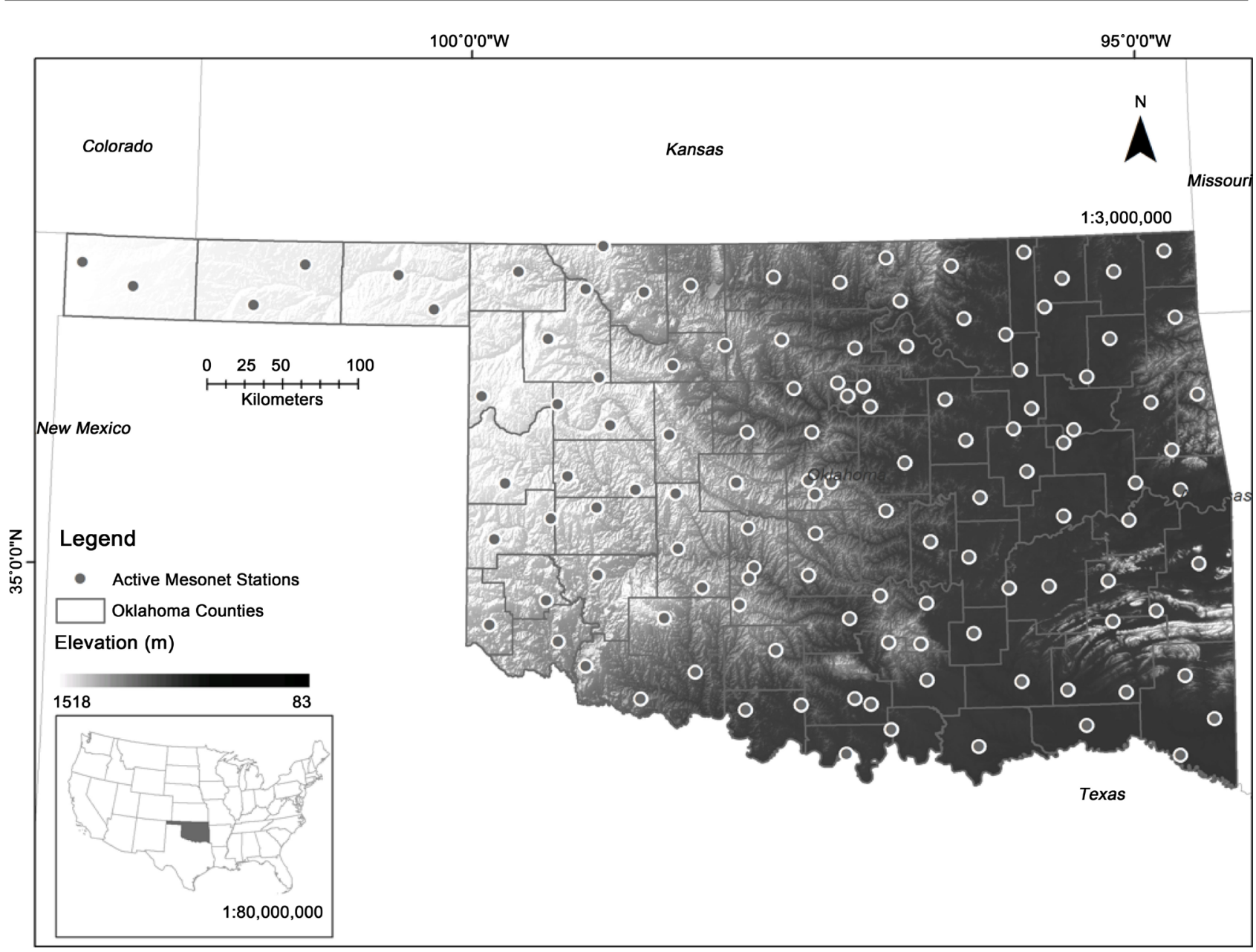

Figure 2. Map of study area and geographical locations of the Mesonet sites within Oklahoma used in winter wheat yield simulation. 
as representative of the soil type. Information on several soil physical and chemical properties that serve as inputs for CERES-wheat were extracted from the gSSURGO data. The data included upper and lower depths for each horizon (cm); sand, silt, and clay percentage; bulk density (0.33 bar); pH in water. Soil profile data for each horizon was created. The Quad UI tool

(http://tools.agmip.org/quadui.php) from the Agricultural Model Intercomparison and Improvement Project (AgMIP), a desktop application for windows system, was used to convert gSSURGO soil database for each site to DSSAT-ready soil data format.

\subsection{Climate Data}

\subsubsection{Baseline Climate Data}

Robust crop yield prediction can be performed when the crop simulation is driven by long term ( $>30$ years) daily weather data. Crop modeling system to analyze crop yields and examine future climatic impacts on a regional level requires detailed weather data on a daily basis on a higher temporal and/or spatial resolution. For baseline weather data, two data sources were used, Daymet [28] and the Oklahoma Mesonet [29]. The Daymet weather data were downloaded in the form of tarred netCDF tiles for the state of Oklahoma. Values for weather variables, minimum and maximum temperature, rainfall, and incident solar radiation, and day-length from 1980-2014 were extracted at the Mesonet site locations. Information on day length was acquired to convert the incident shortwave radiation flux density $\left(\mathrm{Wm}^{-2}\right)$. Since the establishment of the Oklahoma Mesonet was initiated during the mid-90s, the Mesonet does not meet the requirements for creating a complete baseline data ( $>30$ years). Therefore, the missing data for each of the Mesonet sites was acquired from its closest National Weather Service (NWS) Cooperative Observer Program (Coop) weather station. As the NWS Coop stations do not measure solar radiation, solar radiation was estimated using RadEst 3.0 [30]. Climate summary files were generated using a python script that produces climate summaries for the 77 sites for both Daymet and Mesonet data. Weather data were processed and adapted to the requirements of the weather input files $\left({ }^{*}\right.$.WTH) for the DSSAT model.

\subsubsection{Generating Future Daily Weather Data}

Regional Climate models have limited applicability because of the computational time involved for properly assigning boundary conditions to a finer-scale weather phenomena [31]. One way to address the issue of inherent uncertainties within the GCMs is to create multi-model ensembles as they overcome the limitations of any single model [32]. Multi-model ensemble averages are found to outperform individual models when tested for the historical period [33]. In addition, they also help distinguish the variability between the models and the uncertainties of future climate [34]. Outputs of 4 GCMs, their ensemble, and ensemble of 17 GCMs were linked to DSSAT to account for the uncertainty of climate projections. Detailed information on forcing data can be found on the 
CMIP5 website (http://cmip-pcmdi.llnl.gov/cmip5/availability.html).

For future climate data, we used data from four state-of-the-art GCMs, HadGEM2-ES, MRI-CGCM3, MRIOC5, and CSIRO-Mk3.6.0 that were included in the Coupled Model Intercomparison Project Phase 5 (CMIP5) [35] (Table 1). The four models were specifically chosen as they had the finest spatial resolution. In addition to the four different GCMs, an ensemble of the four GCMs along with an ensemble of 17 different GCMs were also included to generate climate trajectories from the $5^{\text {th }}$ Assessment Report [8]. Two emission scenarios reported in the Special Report on Emissions scenarios by IPCC were used for downscaling the data for the Mesonet locations. A moderately high (RCP6.0) and high emission scenarios (RCP8.5) were chosen to create weather outputs for 2040 to 2060 for each of the target 77 sites. Choosing multiple RCPs and GCMs allows us to account for uncertainties related to future emissions trajectory as well as the simulated atmospheric response [36]. Unlike current weather data, the projected data should be able to represent a range of future possible scenarios complying with a range of observed and projected statistical characteristics of variable of interest.

Future daily weather data was generated with Marksim v.2 [37]. The Marksim v.2 is a weather generator that produces daily weather variables by mimicking the observed weather variables and their statistical properties. It is a third-order Markov rainfall generator and the program has been calibrated with more than 10,000 stations worldwide, clustered into 702 climate clusters. Current version of Marksim requires the input data from the most recent IPCC AR5 models. Additional parameters such as latitude, longitude, and elevation are required for generating daily-time-step weather data for a given location. MarkSim has been applied to various climate impact studies in agriculture field. Marksim generated future weather data was to estimate the number of Helicoverpa armigera Hub for eight pigeon pea (Cajanus cajan L.) growing locations in India for 2020, 2050, and 2080 [38]. Marksim generated data were also used in studying future

Table 1. Four state-of-the-art general circulation models (GCMs) included in the Coupled Model Intercomparison Project Phase 5 (CMIP5) [13] used in our study.

\begin{tabular}{|c|c|c|c|}
\hline Model Name & $\begin{array}{l}\text { Resolution, } \\
\text { Lat } \times \text { Lon }^{\circ}\end{array}$ & Institution & Reference \\
\hline CSIRO-Mk3.6.0 & $1.875 \times 1.875$ & $\begin{array}{l}\text { Commonwealth Scientific and Industrial } \\
\text { Research Organization and the Queensland } \\
\text { Climate Change Center of Excellence }\end{array}$ & $\begin{array}{c}\text { (Collier et al., } \\
\text { 2011) }\end{array}$ \\
\hline HadGEM2-ES & $1.2414 \times 1.875$ & Met Office Hadley Centre & $\begin{array}{l}\text { (Collins et al., } \\
\text { 2011) }\end{array}$ \\
\hline MIROC5 & $1.4063 \times 1.4063$ & $\begin{array}{l}\text { Japan Agency for Marine-Earth Science and } \\
\text { Technology, Atmosphere and Ocean Research } \\
\text { Institute (The University of Tokyo), and } \\
\text { National Institute for Environmental Studies }\end{array}$ & $\begin{array}{c}\text { (Watanabe et al., } \\
\text { 2010) }\end{array}$ \\
\hline MRI-CGCM3 & $1.125 \times 1.125$ & Meteorological Research Institute & $\begin{array}{c}\text { (Yukimoto et al., } \\
\text { 2012) }\end{array}$ \\
\hline
\end{tabular}


availability of recreational cultural ecosystem services with changing climate [39]. Marksim was used to generate 21 independent climate years with 30 replications to achieve a maximum inter-annual weather variability and gain better insight into future weather patterns. Creation of DSSAT weather data file format "*.WTG" using Marksim was automated and the program was executed with different seed values (starting value used by a random number generation routine to crease random numbers) for each of the 30 replications of weather file. No bias correction with respect to the baseline climatology were applied to the downscaled GCM data.

\subsection{Model Inputs}

A total of six future climate scenarios (four GCMs, their ensemble, and the ensemble of all available GCMs in the CMIP5 projection data) were used for RCP6.0 and RCP8.5. Future atmospheric $\mathrm{CO}_{2}$ concentration used in the simulations were obtained from the freely available RCP Database v2.0.5

(http://tntcat.iiasa.ac.at:8787/RcpDb/dsd?Action=htmlpage\&page=download).

Time for emergence, anthesis, physiological maturity and wheat yield were calculated for each year of the baseline and future scenarios. Cropping system in Oklahoma and most part of the Southern Plains is done under water limited conditions. The region has faced several severe droughts, including the recent drought of 2012. Therefore, simulations were designed by considering both non-limiting and limiting growing conditions. Three scenarios of wheat growing conditions were simulated, i) Actual $\left(\mathrm{Y}_{w f}\right)$-with water and nitrogen limiting conditions, ii) Attainable $\left(\mathrm{Y}_{\mathrm{a}}\right)$-nitrogen limiting condition, and iii) Potential $\left(\mathrm{Y}_{p}\right)$-non-limiting conditions.

\subsection{Computational Requirements}

There were total of 1080 individual runs for 1617 locations-years, which included 30 replications. Running simulation on a personal computer would require a significant amount of time. Therefore, the simulations were executed on Linux cluster at the High Performance Computing Center, Oklahoma State University. Replicates were averaged for each year for a location. Performing such a large simulation required 72 nodes and a total of 96-hour wall-clock time was needed to complete the simulations.

\subsection{Model Evaluation}

Model performance was evaluated by comparing simulated and the USDANASS reported winter wheat yields for the entire 35-year period. Wheat yield was investigated across the state at a fine resolution using the DSSAT-CERES Wheat model and the outputs of 4 GCMs, their ensemble, and ensemble of 17 GCMs under RCP6.0 and RCP8.5 scenarios. We used two different baseline datasets, one derived from the Oklahoma Mesonet and the other from DAYMET dataset. Considering data source, GCMs, forcing scenarios, and yield scenarios, 
simulation were carried out for 72 factors for 77 sites for 20 years. Simulation were replicated 30 times with the weather data generated using different seed number for each location. For analysis purpose, simulation output for the replications were averaged and yield across the sites were averaged for each year and plotted.

\section{Results and Discussion}

The crux of this manuscript is to assess how the DSSAT-CERES-Wheat crop model predicts wheat yield and yield changes when the model is driven by different downscaled GCMs and their ensembles across two different RCPs. Fewer studies have assessed wheat yield performance on such a finer scale. Hence, the result and discussion section will mostly focus on the differences between the projected yield changes compared with the baseline scenario yield rather than crop phenology and physiology.

\subsection{Projected Climate Change}

Both baseline data looked similar in distribution (Table 2). However, the distribution of Daymet recorded SRAD for baseline show higher values compared to Mesonet. Distribution of downscaled annual average data show higher variability in terms of data distribution compared to the observed baseline (Figure 3). In

Table 2. Baseline (1980-2014) average annual summary for rainfall, solar radiation, maximum and minimum temperature for Daymet and Mesonet Data at 77 Mesonet sites in Oklahoma.

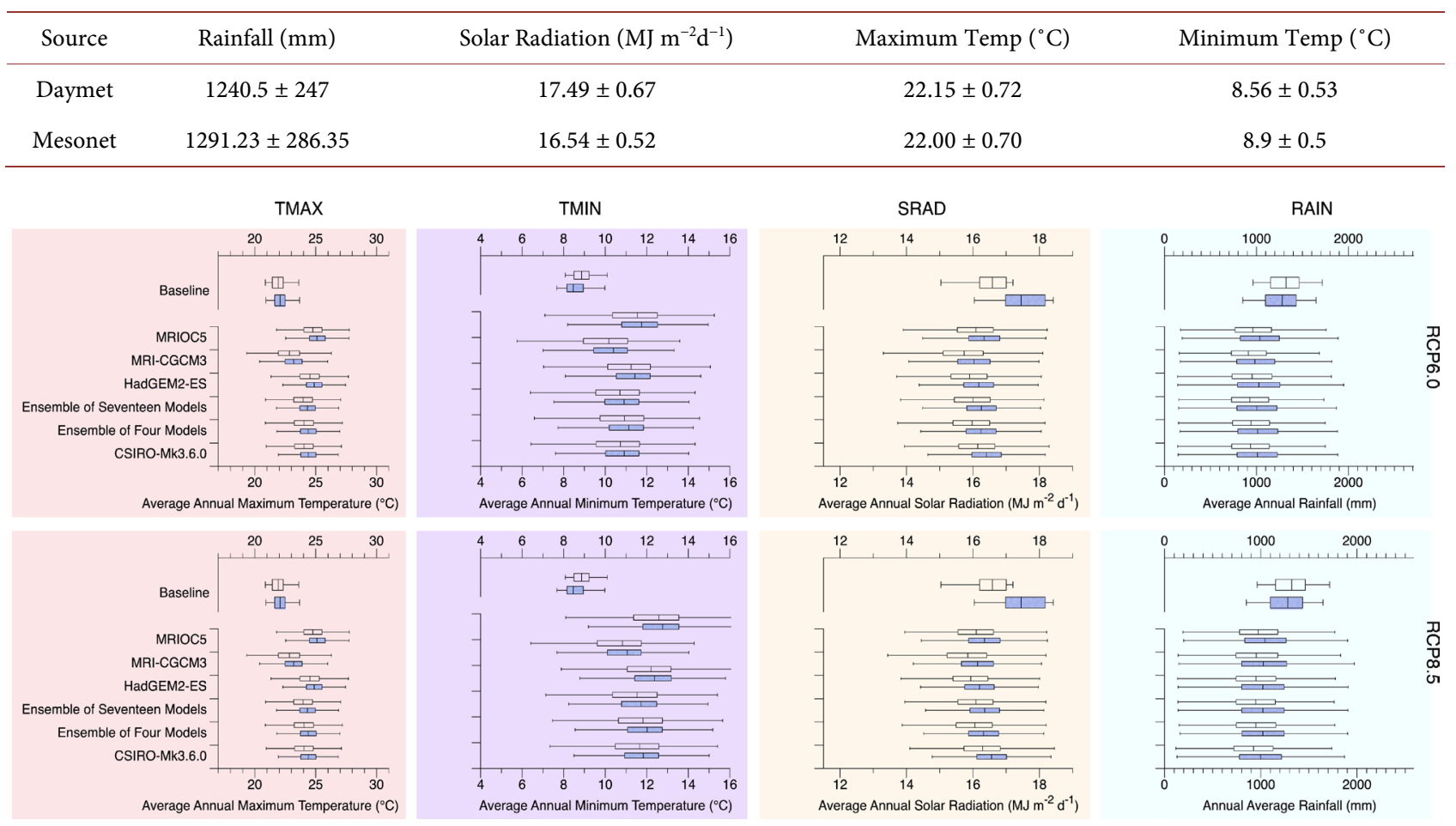

Figure 3. Distribution of annual averages of maximum temperature, minimum temperature, solar radiation, and total rainfall downscaled using Marksim for the period 2040-2060 under two RCP forcings of 6.0 and 8.5 along with baseline (1980-2014) weather data for two different weather data sources: Mesonet and Daymet. Data are averaged across select 77 Mesonet locations. 
addition, median values of Daymet data appear higher than Mesonet data for most of the time. Projected average annual weather data for RCP6.0 and RCP8.5 show increase in temperature (maximum and minimum), and decrease in solar radiation and total rainfall amount (Figure 3). Percent increase or decrease of projected four weather variables for their corresponding GCMs and RCPs compared to the baseline data of Mesonet and Daymet are summarized in Table 3. Percent changes of average annual rainfall, solar radiation, maximum temperature, and minimum temperature relative to the baseline climate. On average, for RCP6.0 forcing, across the different GCMs, Daymet generated projection show $17.72 \% \pm 1.24 \%$ decline in average total rainfall amount while Mesonet generated projection show $26.7 \% \pm 1.24 \%$ decline in average total rainfall amount relative to their baseline values. Likewise, for RCP8.5 forcing, average total rainfall is expected to decline by $16.84 \% \pm 1.77 \%$ and $25.70 \pm 1.42$ using Daymet and Mesonet data respectively.

In case of SRAD, the values are projected to decline at a range of $3.15 \%$ $7.15 \%$ in relation to the baseline data, with a higher reduction for RCP6.0 forcing. Maximum temperature is projected to increase up to $10.13 \%$ for RCP 6.0 and $14.44 \%$ for RCP8.5. On an average, rise in maximum temperature was projected to be approximately $2.11^{\circ} \mathrm{C}$ RCP 6.0 and $3.04^{\circ} \mathrm{C}$ for RCP8.5. However, a greater increase in minimum temperature is projected, ranging from $19.59 \%$ $36.61 \%$. Increase of an average of $2.0^{\circ} \mathrm{C}$ was computed for the RCP6.0 forcing and $2.88^{\circ} \mathrm{C}$ forRCP8.5 forcing. Higher percentages are observed for RCP8.5 forcing. Coefficient of variation (CV, \%) for all the estimates average ranged somewhere between 0.82 - 5.34. CV were lowest for SRAD, followed by RAIN, TMAX, and TMIN. In addition, CV were lower for RCP6.0 compared to RCP8.5 for the four weather variables.

\subsection{Future Wheat Yield Simulation}

For each site, historical yield was averaged across the 1984-2014 (Figure 4) and future yields were averaged across 30 different replications for each site for each year and plotted (Figure 5). Compared to the baseline yield, downscaled GCMs using Daymet data, under RCP6.0 forcing showed average increase in wheat yield by $9.65 \%, 2.46 \%$, for $\mathrm{Y}_{w f}$ and $\mathrm{Y}_{a}$ scenario respectively. However, average decrease of $7.45 \%$ in yield was projected for $\mathrm{Y}_{p}$ scenarios. Under RCP8.5 forcing, increase in yield was observed across three yield scenarios, ranging between $4.26 \%-19.68 \%$ (Table 4).

There is a consistency in the projected winter wheat yield between the GCMs. Across all the yield scenarios and under the forcing scenarios of RCP6.0 and RCP8.5, MRIOC5 consistently has the lowest yield. The yields converge for $\mathrm{Y}_{w f}$ scenario, however, the difference between the GCMs and between the data sources increase for $\mathrm{Y}_{a}$ and $\mathrm{Y}_{p}$ scenarios under both RCP forcings. However, we can't identify which downscaled GCM is performing better. One way to further improve the credibility of this study is to generate downscaled data for each of 
Table 3. Percent changes of average annual rainfall, solar radiation, maximum temperature, and minimum temperature relative to the baseline climate.

\begin{tabular}{|c|c|c|c|c|}
\hline \multirow[t]{2}{*}{ Variables } & \multicolumn{2}{|c|}{ RCP6.0 } & \multicolumn{2}{|c|}{ RCP8.5 } \\
\hline & Daymet & Mesonet & Daymet & Mesonet \\
\hline \multicolumn{5}{|l|}{ Rainfall (mm) } \\
\hline CSIRO-Mk3.6.0 & -18.24 & -27.10 & -19.18 & -27.91 \\
\hline Ensemble of Four Models & -17.59 & -26.51 & -16.94 & -25.79 \\
\hline Ensemble of Seventeen Models & -18.57 & -27.45 & -17.20 & -26.09 \\
\hline HadGEM2-ES & -16.85 & -25.78 & -17.09 & -25.91 \\
\hline MRI-CGCM3 & -19.23 & -28.09 & -15.90 & -24.95 \\
\hline MRIOC5 & -15.82 & -24.65 & -14.77 & -23.57 \\
\hline Average & $-17.72 \pm 1.24$ & $-26.60 \pm 1.24$ & $-16.84 \pm 1.47$ & $-25.70 \pm 1.42$ \\
\hline Coefficient of variation (\%) & 1.51 & 1.69 & 1.77 & 1.92 \\
\hline \multicolumn{5}{|l|}{ Solar Radiation $\left(\mathrm{MJ} \mathrm{m}^{-2} \mathrm{~d}^{-1}\right)$} \\
\hline CSIRO-Mk3.6.0 & -6.20 & -2.70 & -5.32 & -1.73 \\
\hline Ensemble of Four Models & -7.12 & -3.67 & -6.69 & -3.13 \\
\hline Ensemble of Seventeen Models & -7.04 & -3.51 & -6.50 & -2.92 \\
\hline HadGEM2-ES & -7.54 & -4.12 & -7.41 & -3.81 \\
\hline MRI-CGCM3 & -8.39 & -5.18 & -7.77 & -4.49 \\
\hline MRIOC5 & -6.62 & -2.94 & -6.62 & -2.84 \\
\hline Average & $-7.15 \pm 0.76$ & $-3.69 \pm 0.89$ & $-6.72 \pm 0.85$ & $-3.15 \pm 0.94$ \\
\hline Coefficient of variation (\%) & 0.82 & 0.93 & 0.91 & 0.97 \\
\hline \multicolumn{5}{|l|}{ Maximum Temperature $\left({ }^{\circ} \mathrm{C}\right)$} \\
\hline CSIRO-Mk3.6.0 & 10.18 & 9.07 & 15.13 & 13.94 \\
\hline Ensemble of Four Models & 10.18 & 9.06 & 14.56 & 13.38 \\
\hline Ensemble of Seventeen Models & 9.89 & 8.77 & 13.81 & 12.62 \\
\hline HadGEM2-ES & 12.34 & 11.24 & 17.16 & 15.98 \\
\hline MRI-CGCM3 & 4.64 & 3.49 & 7.69 & 6.51 \\
\hline MRIOC5 & 13.54 & 12.44 & 18.27 & 17.07 \\
\hline Average & $10.13 \pm 3.06$ & $9.01 \pm 3.07$ & $14.44 \pm 3.70$ & $13.25 \pm 3.70$ \\
\hline Coefficient of variation (\%) & 2.78 & 2.82 & 3.22 & 3.27 \\
\hline \multicolumn{5}{|l|}{ Minimum Temperature $\left({ }^{\circ} \mathrm{C}\right)$} \\
\hline CSIRO-Mk3.6.0 & 24.45 & 17.92 & 35.32 & 28.37 \\
\hline Ensemble of Four Models & 26.59 & 19.98 & 37.14 & 30.12 \\
\hline Ensemble of Seventeen Models & 24.18 & 17.66 & 33.95 & 27.06 \\
\hline HadGEM2-ES & 30.73 & 23.96 & 42.11 & 34.90 \\
\hline MRI-CGCM3 & 17.34 & 11.07 & 25.14 & 18.58 \\
\hline MRIOC5 & 33.83 & 26.94 & 45.97 & 38.62 \\
\hline Average & $26.19 \pm 5.74$ & $19.59 \pm 5.52$ & $36.61 \pm 7.19$ & $29.61 \pm 6.92$ \\
\hline Coefficient of variation (\%) & 4.55 & 4.62 & 5.26 & 5.34 \\
\hline
\end{tabular}




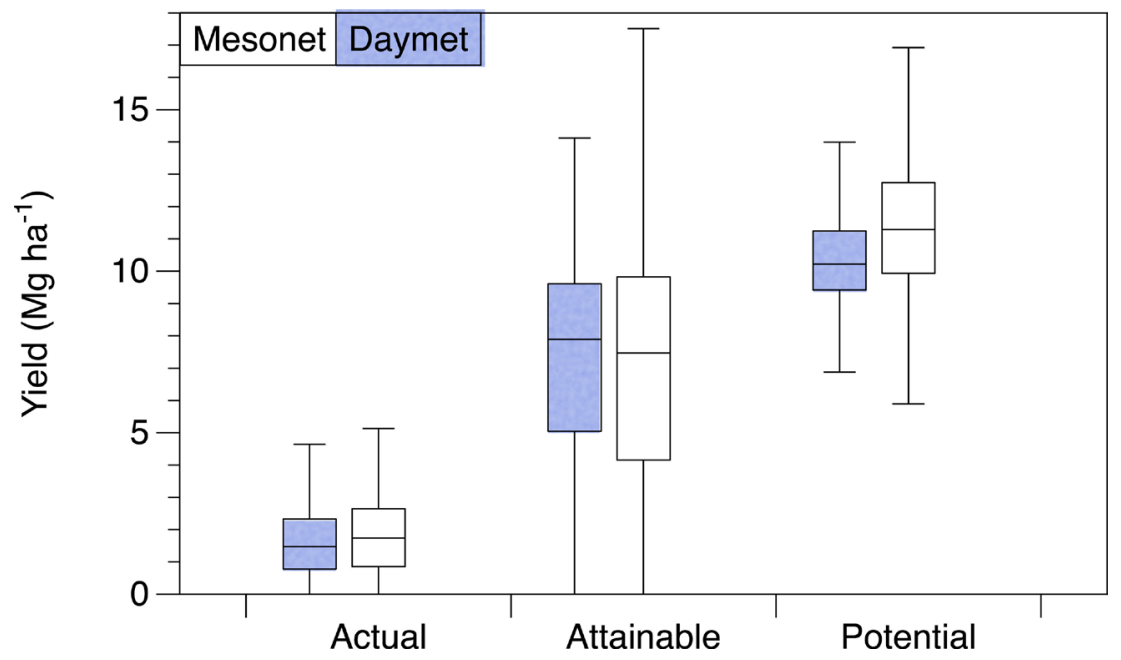

Figure 4. Box-and-whisker plots of DSSAT simulated winter wheat yield during the 30-year (1984-2014) at 77 different Mesonet locations in Oklahoma for three yield scenarios, i) Actual $\left(\mathrm{Y}_{w f}\right)$-water and nitrogen limiting, ii) Attainable $\left(\mathrm{Y}_{a}\right)$-nitrogen limiting, and iii) Potential $\left(\mathrm{Y}_{p}\right)$-non-limiting conditions using two different weather data sources, Daymet (shaded blue) and Mesonet. From top to bottom the horizontal lines in the box plots show the $95^{\text {th }}, 75^{\text {th }}, 50^{\text {th }}, 25^{\text {th }}$, and $5^{\text {th }}$ percentiles.
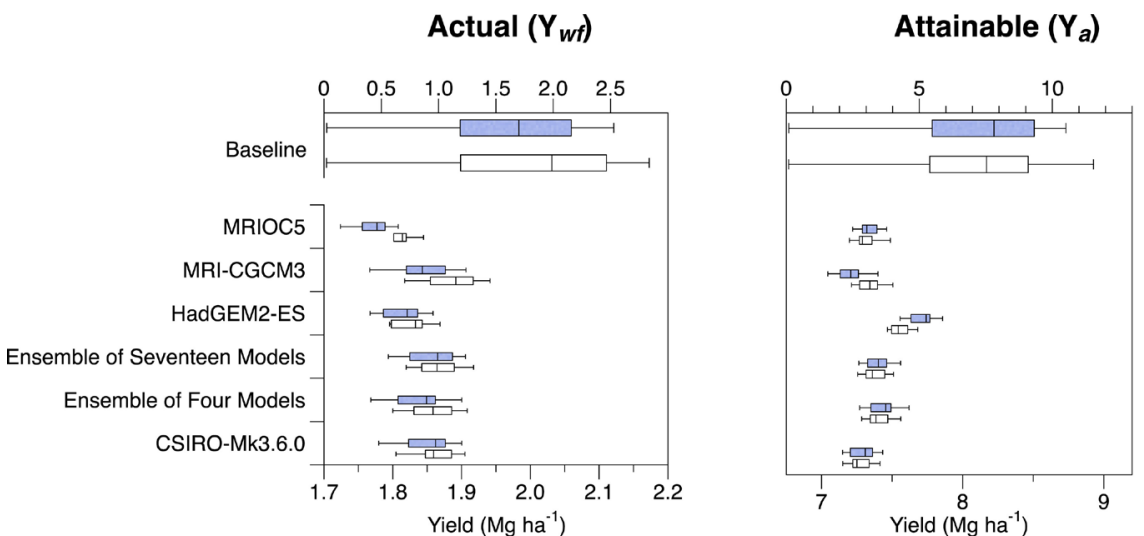

Potential $\left(\mathbf{Y}_{p}\right)$
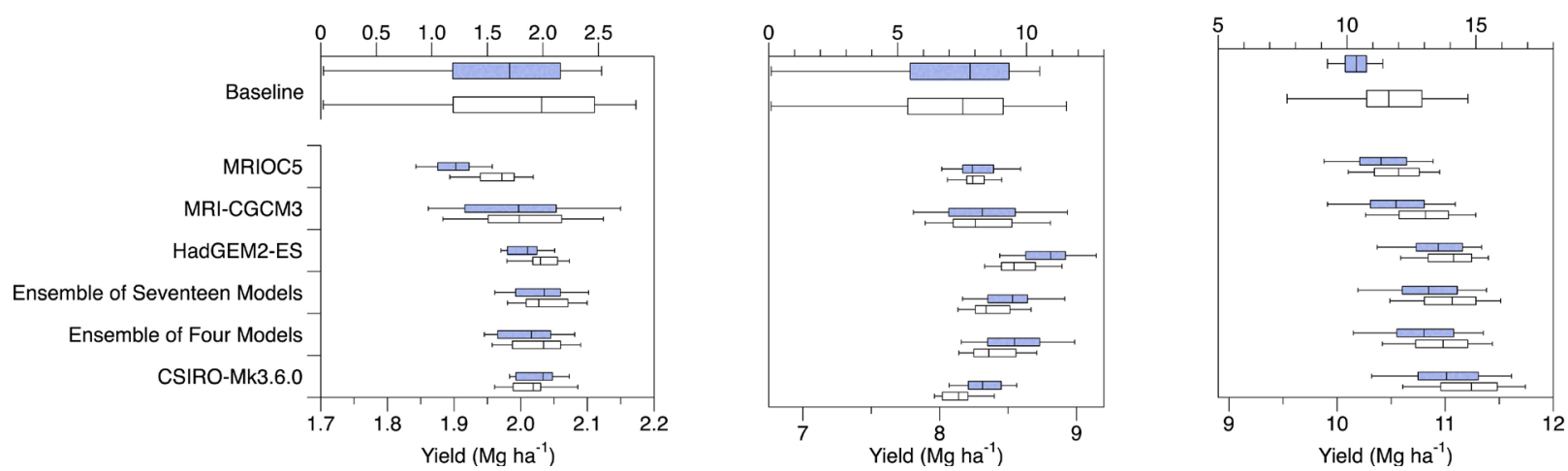

Figure 5. Projected winter wheat yield of 2040-2060 relative to 1980-2014, averaged from 77 locations across the Oklahoma Mesonet locations using different GCMs, their ensembles under the forcing scenarios of RCP6.0 and RCP8.5.

the RCPs for baseline time period, compute the annual mean and compare against the known baseline mean weather data [38]. In addition, yield can be also compared across different downscaled GCMs in order to identify model that 
Table 4. Percent change of simulated winter grain yield for the period 2040-2060 relative to the baseline climate (1980-2014) using different General Circulation Models (GCMs) and Representative Concentration Pathways (RCPs) 6.0 and 8.5 for three different growing scenarios: actual $\left(\mathrm{Y}_{w f}\right)$, attainable $\left(\mathrm{Y}_{a}\right)$, and potential $\left(\mathrm{Y}_{p}\right)$.

\begin{tabular}{|c|c|c|c|c|c|c|c|}
\hline \multirow{2}{*}{ Source } & \multirow{2}{*}{ GCMs } & \multicolumn{3}{|c|}{ RCP6.0 } & \multicolumn{3}{|c|}{ RCP8.5 } \\
\hline & & $\mathbf{Y}_{w f}$ & $\mathrm{Y}_{\mathrm{a}}$ & $\mathrm{Y}_{p}$ & $\mathbf{Y}_{w f}$ & $\mathrm{Y}_{\mathrm{a}}$ & $\mathrm{Y}_{p}$ \\
\hline \multirow{8}{*}{ Daymet } & CSIRO-Mk3.6.0 & 11.01 & 1.00 & -6.63 & 21.75 & 15.33 & 6.76 \\
\hline & Ensemble of four models & 10.18 & 2.98 & -7.21 & 20.96 & 18.53 & 4.71 \\
\hline & Ensemble of seventeen models & 11.37 & 2.54 & -7.08 & 21.89 & 18.09 & 5.07 \\
\hline & HadGEM2-ES & 8.72 & 6.77 & -3.86 & 20.47 & 21.93 & 5.85 \\
\hline & MRI-CGCM3 & 10.20 & -0.18 & -11.13 & 19.18 & 15.49 & 2.24 \\
\hline & MRIOC5 & 6.39 & 1.62 & -8.76 & 13.83 & 14.82 & 0.95 \\
\hline & Average & 9.65 & 2.46 & -7.45 & 19.68 & 17.37 & 4.26 \\
\hline & CSIRO-Mk3.6.0 & -0.85 & 3.34 & -15.13 & 7.72 & 15.78 & -4.14 \\
\hline \multirow{6}{*}{ Mesonet } & Ensemble of four models & -1.17 & 5.24 & -15.96 & 8.08 & 19.32 & -6.29 \\
\hline & Ensemble of seventeen models & -0.54 & 4.77 & -15.53 & 8.57 & 19.17 & -5.62 \\
\hline & HadGEM2-ES & -2.68 & 7.27 & -13.59 & 8.23 & 21.81 & -5.63 \\
\hline & MRI-CGCM3 & 0.17 & 4.29 & -18.81 & 6.25 & 18.38 & -7.68 \\
\hline & MRIOC5 & -3.71 & 3.91 & -17.45 & 4.47 & 17.30 & -9.84 \\
\hline & Average & -1.47 & 4.80 & -16.08 & 7.22 & 18.63 & -6.53 \\
\hline
\end{tabular}

explains the weather pattern better in this region.

Comparison of seasonal cumulative rainfall and crop evapotranspiration averages across all the site, years showed that most of the instances, evapotranspiration values were always less than rainfall across all the downscaled GCM weather data, radiative forcings, and baseline data sources (Table 5). Average seasonal rainfall for simulations performed with Daymet baseline weather data for $\mathrm{Y}_{w f}$ yield scenario and RCP6.0 was $569.39 \pm 16.75 \mathrm{~mm}$ for which the estimated evapotranspiration value was $375.98 \pm 2.34 \mathrm{~mm}$. For the same simulation scenario under RCP8.5 forcing, the seasonal average rainfall value was $566.98 \pm$ $22.98 \mathrm{~mm}$ with an estimated crop evapotranspiration value of $373.66 \pm 4.36 \mathrm{~mm}$. These values are similar to the baseline seasonal rainfall $(561 \pm 137 \mathrm{~mm})$ and evapotranspiration $(375 \pm 46.58 \mathrm{~mm}$ ) for both Daymet and Mesonet data (values not shown). Comparison of number of days from planting to harvest showed that the duration decreased under projected climate data (Table 6). This could result from increase in temperature stress. As the crop senses stress, it is more likely to shorten its life cycle, causing an undesirable increase in wheat grain protein content [13] [14].

Results from our simulation are similar to those reported by [40]. Using the downscaled data from the Regional Climate Models CanESM2 and CANRCM4 and DSSAT-CERES-Wheat model, they report an increase in spring wheat yield between $10 \%$ and $20 \%$ averaged across the Canadian Prairies. However, yield in 
Table 5. Average growing season rainfall and average crop evapotranspiration generated from DSSAT-CERES-Wheat simulation performed by using six different Global Circulation Models (GCMs) under two different forcings of RCP using two different baseline data sources for actual $\left(\mathrm{Y}_{p}\right)$ and attainable $\left(\mathrm{Y}_{p}\right)$ growing scenarios. Values are averaged across 77 different Mesonet locations.

\begin{tabular}{|c|c|c|c|c|c|c|c|}
\hline \multirow{3}{*}{ Source } & \multirow{3}{*}{ GCMS } & \multicolumn{3}{|c|}{ RCP6.0 } & \multicolumn{3}{|c|}{ RCP8.5 } \\
\hline & & \multirow{2}{*}{ Avg. Rain (mm) } & $\mathrm{Y}_{w f}$ & $\mathrm{Y}_{a}$ & \multirow{2}{*}{ Avg. Rain (mm) } & $\mathrm{Y}_{w f}$ & $\mathrm{Y}_{a}$ \\
\hline & & & Avg. ET (mm) & Avg. ET (mm) & & Avg. ET (mm) & Avg. ET (mm) \\
\hline \multirow{6}{*}{ Daymet } & MRI-CGCM3 & 604.36 & 376.39 & 402.61 & 596.70 & 377.07 & 404.55 \\
\hline & MRIOC5 & 553.68 & 371.32 & 397.42 & 565.09 & 364.62 & 390.91 \\
\hline & HadGEM2-ES & 568.08 & 375.25 & 401.09 & 586.71 & 376.76 & 400.69 \\
\hline & CSIRO-Mk3.6.0 & 555.24 & 378.50 & 403.15 & 524.21 & 372.06 & 395.98 \\
\hline & Ensemble of four models & 568.95 & 376.50 & 402.04 & 567.18 & 375.47 & 400.65 \\
\hline & Ensemble of seventeen models & 566.01 & 377.94 & 402.97 & 559.06 & 375.96 & 401.01 \\
\hline \multirow{6}{*}{ Mesonet } & MRI-CGCM3 & 559.13 & 378.01 & 408.25 & 557.68 & 376.89 & 408.36 \\
\hline & MRIOC5 & 520.33 & 369.67 & 401.87 & 534.30 & 368.36 & 399.80 \\
\hline & HadGEM2-ES & 528.41 & 373.79 & 404.55 & 548.61 & 376.85 & 405.49 \\
\hline & CSIRO-Mk3.6.0 & 514.92 & 374.88 & 404.61 & 488.57 & 369.85 & 397.56 \\
\hline & Ensemble of four models & 529.24 & 375.00 & 405.41 & 529.76 & 373.75 & 403.48 \\
\hline & Ensemble of seventeen models & 525.55 & 375.09 & 405.06 & 521.98 & 374.47 & 404.08 \\
\hline
\end{tabular}

Table 6. Median number of days between sowing and harvest for winter wheat, over the baseline period 1980-2014 and future climate projections 2040-2060 under three different growing scenarios, actual $\left(\mathrm{Y}_{w f}\right)$, attainable $\left(\mathrm{Y}_{a}\right)$, and potential $\left(\mathrm{Y}_{p}\right)$.

\begin{tabular}{|c|c|c|c|c|c|}
\hline \multirow{2}{*}{ Yield Scenario } & \multirow{2}{*}{ Climate Scenario } & \multicolumn{2}{|c|}{ RCP6.0 } & \multicolumn{2}{|c|}{ RCP8.5 } \\
\hline & & Daymet & Mesonet & Daymet & Mesonet \\
\hline \multirow{7}{*}{$\mathbf{Y}_{w f}$} & Baseline & 225 & 225 & 225 & 225 \\
\hline & MRI-CGCM3 & 223 & 225 & 221 & 223 \\
\hline & MRIOC5 & 214 & 216 & 211 & 212 \\
\hline & HadGEM2-ES & 217 & 219 & 214 & 215 \\
\hline & CSIRO-Mk3.6.0 & 218 & 220 & 214 & 216 \\
\hline & Ensemble of four models & 218 & 220 & 215 & 217 \\
\hline & Ensemble of seventeen models & 219 & 221 & 215 & 217 \\
\hline \multirow{7}{*}{$\mathrm{Y}_{\mathrm{a}}$} & Baseline & 225 & 225 & 225 & 225 \\
\hline & MRI-CGCM3 & 223 & 225 & 221 & 223 \\
\hline & MRIOC5 & 214 & 216 & 211 & 212 \\
\hline & HadGEM2-ES & 217 & 219 & 214 & 215 \\
\hline & CSIRO-Mk3.6.0 & 218 & 220 & 214 & 216 \\
\hline & Ensemble of four models & 218 & 220 & 215 & 217 \\
\hline & Ensemble of seventeen models & 219 & 221 & 215 & 217 \\
\hline \multirow{7}{*}{$\mathrm{Y}_{p}$} & Baseline & 226 & 233 & 225 & 225 \\
\hline & MRI-CGCM3 & 224 & 226 & 221 & 224 \\
\hline & MRIOC5 & 214 & 216 & 211 & 212 \\
\hline & HadGEM2-ES & 218 & 219 & 214 & 215 \\
\hline & CSIRO-Mk3.6.0 & 218 & 220 & 214 & 216 \\
\hline & Ensemble of four models & 218 & 220 & 215 & 217 \\
\hline & Ensemble of seventeen models & 219 & 221 & 216 & 217 \\
\hline
\end{tabular}


the northern latitudes are projected to increase. DeNitrofication-DeComposition (DNDC) model used to simulate spring wheat yield under projected climatic conditions found that yield increased across IPCC SRES climate change scenarios [41]. Previous study in wheat productivity in Central Oklahoma also reported some small changes in wheat yield $\pm 5 \%$, with a $5 \%$ decrease in B2a scenario and 5\% increase in GGal scenarios. Increase in yield could be due to the direct physiological effects of the increased atmospheric conditions.

The significance of this study is that it helps to evaluate the potential impacts of future climate change on wheat enterprise on a local scale on different temporal scales. There are no tools currently available for preparing future weather input files from observed weather data on a local level. We undertook a spatially explicit simulation to assess how winter wheat productivity might be impacted by mid- $21^{\text {st }}$ century climate change. Simulations were carried out for 77 target Mesonet location across the State of Oklahoma. Some of the existing limitations in the model is that the crop model currently does not simulate the effect of high temperatures on pollen viability; the effect of $\mathrm{CO}_{2}$ on other processes besides photosynthesis and transpiration; and the interaction between temperature, drought, and increased $\mathrm{CO}_{2}$ concentration [42]. Likewise, uncertainties in our study reside in the prediction of the climate models used, location of site used for simulation, and simulation output of the DSSAT model. Management practices, fertilizer inputs, and cultivar were set constant and were not changed from our baseline simulations. Therefore, the results may not hold under similar climatic conditions. We also need to stress that these simulations do not take into account of pests and disease potentials, and loss due to natural calamities such as flooding. The idea of using scenarios is not to predict future but to better understand the uncertainties for judicious decision making for a range of future conditions. In our study, we chose only two scenarios to work with because of computational and storage resources and time limitations. However, we should also keep in mind that the greater proportion of uncertainty in climate change impact assessment has been credited to variations among crop models rather than variations among the downscaled GCMs [43]. Our objective was not to compare the differences between the crop models, but to examine the yield differences across future climate projection based on the downscaled GCMs and their ensembles.

Although simulations suggest yield increase, further study is required to examine how soil quality and additional challenges of pest, irrigation, soil degradation, etc. may impact sustained crop production on a regional level. Also, study must verify if lodging may become issue for $\mathrm{Y}_{a}$ and $\mathrm{Y}_{p}$ scenarios. We only examined the annual mean data across the sites, however, the crop is sensitive to fluctuation in weather variation depending on the growth stage. Water availability for crop production in future is also uncertain, therefore, crop production with less water can be problematic if the temperature is also hotter. Since Marksim is an example of a stochastic, statistical downscaling method, with low input 
data requirement to quantify the relationship between crop growth and weather, it may be less adaptable to different climatic conditions both spatially and temporally [44]. And process-based models such as the DSSAT CERES-Wheat include more non-linear processes, so that the spatial aggregation of inputs over heterogeneous landscape is less recommended [18] [25].

\section{Conclusion}

This paper describes a methodology for rapid synthesis of GCM-based, spatially explicit, high resolution future weather data inputs for the DSSAT crop model, for cropland area across wheat growing regions of Oklahoma on a seamless temporal scale. We examined how climate change may impact regional food security using a "bottom-up" approach. Most previous studies have focused on how climate change influence crop yield at regional and/or national levels. This study is a marked advance in the compilation of high resolution dataset, as such data offers tremendous opportunity to quantify future yield status for other crops within the region. With advancement in climate models in term of their fidelity in simulating natural processes and generating reliable output at higher spatio-temporal scales, we would be able to better assess the magnitude of the impact of climate changes on crop production and its societal impact. Based on our experience in implementing simulations for multi decadal, fine-scale study, we argue that a good understanding of scientific computing along with crop science and physiology is extremely helpful from crop modeling perspective. Focus on replicability, transparency, and code efficiency are seldom discussed in the literature. We believe that addressing these aspects is also of significance importance for advancement in crop modeling. Therefore, we conclude that by minimizing the yield gap with improved crop husbandry, increased input efficiency for water, nutrients, and pesticides, along with improved wheat cultivars, and sustainable production practice, wheat production in this region can be sustained for changing climate to meet the nutritional demand of people in years to come.

\section{Acknowledgements}

We acknowledge at support from Oklahoma Agricultural Experiment Station, Hatch project \#2939; Oklahoma Wheat Commission, the National Science Foundation Grant No. OIA-1301789 and the OSU High Performance Computing Center through NSF Grant No. OCI-1126330 for providing the computational resources required for this study.

\section{References}

[1] USDA (2017) World Agricultural Supply and Demand Estimates Report (WASDE). United States Department of Agriculture. http://www.usda.gov/oce/commodity/wasde/latest.pdf

[2] USDA-NASS (2017) United States Department of Agriculture Data and Statistics. 
http://www.nass.usda.gov/Quick_Stats/Lite/

[3] Godfray, H.C.J., Crute, I.R., Beddington, J.R., et al. (2010) Food Security: The Challenge of Feeding 9 Billion People. Science, 327, 812-818.

https://doi.org/10.1126/science.1185383

[4] Olmstead, A.L. and Rhode, P.W. (2011) Adapting North American Wheat Production to Climatic Challenges, 1839-2009. Proceedings of the National Academy of Sciences of the United States of America, 108, 480-485.

https://doi.org/10.1073/pnas.1008279108

[5] IPCC (2012) Summary for Policymakers. In: Field, C.B., Barros, V., Stocker, T.F., Qin, D., Dokken, D.J., Ebi, K.L., Mastrandrea, M.D., Mach, K.J., Plattner, G.-K., Allen, S.K., Tignor, M. and Midgley, P.M., Eds., Managing the Risks of Extreme Events and Disasters to Advance Climate Change Adaptation, A Special Report of Working Groups I and II of the Intergovernmental Panel on Climate Change, Cambridge University Press, Cambridge, UK, New York, NY, 582 p.

[6] Hansen, J.W. and Indeje, M. (2004) Linking Dynamic Seasonal Climate Forecasts with Crop Simulation for Maize Yield Prediction in Semi-Arid Kenya. Agricultural and Forest Meteorology, 125, 143-157.

https://doi.org/10.1016/j.agrformet.2004.02.006

[7] Maraun, D., Wetterhall, F., Ireson, A.M., et al. (2010) Precipitation Downscaling under Climate Change: Recent Developments to Bridge the Gap between Dynamical Models and the End User. Reviews of Geophysics, 48, 1-34.

https://doi.org/10.1029/2009RG000314

[8] Field, C.B., Barros, V.R., Dokken, D.J., Mach, K.J., Mastrandrea, M.D., Bilir, T.E., Chatterjee, M., Ebi, K.L., Estrada, Y.O., Genova, R.C., Girma, B., Kissel, E.S., Levy, A.N., MacCracken, S., Mastrandrea, P.R. and White, L.L. (2014) Climate Change 2014: Impacts, Adaptation, and Vulnerability: Part A: Global and Sectoral Aspects. Contribution of Working Group II to the Fifth Assessment Report of the Intergovernmental Panel on Climate Change, Cambridge University Press, Cambridge, UK, New York, NY, 1132 p.

[9] Lobell, D.B. and Field, C.B. (2007) Global Scale Climate-Crop Yield Relationships and the Impacts of Recent Warming. Environmental Research Letters, 2, Article ID: 011002. https://doi.org/10.1088/1748-9326/2/1/014002

[10] Lobell, D.B., Sibley, A. and Ivan Ortiz-Monasterio, J. (2012) Extreme Heat Effects on Wheat Senescence in India. Nature Climate Change, 2, 186-189.

https://doi.org/10.1038/nclimate1356

[11] Long, S.P., Ainsworth, E.A., Leakey, A.D.B., Nösberger, J. and Ort, D.R. (2006) Food for Thought: Lower-Than-Expected Crop Yield Stimulation with Rising $\mathrm{CO}_{2}$ Concentrations. Science, 312, 1918-1921.

[12] Asseng, S., Ewert, F., et al. (2015) Rising Temperatures Reduce Global Wheat Production. Nature Climate Change, 5, 143-147. https://doi.org/10.1038/nclimate2470

[13] Gooding, M.J., Ellis, R.H., Shewry, P.R. and Schofield, J.D. (2003) Effects of Restricted Water Availability and Increased Temperature on the Grain Filling, Drying and Quality of Winter Wheat. Journal of Cereal Science, 37, 295-309.

https://doi.org/10.1006/jcrs.2002.0501

[14] Wahid, A., Gelani, S., Ashraf, M. and Foolad, M.R. (2007) Heat Tolerance in Plants: An Overview. Environmental and Experimental Botany, 61, 199-223. https://doi.org/10.1016/j.envexpbot.2007.05.011

[15] Lobell, D.B., Schlenker, W. and Costa-Roberts, J. (2011) Climate Trends and Global Crop Production Since 1980. Science, 333, 616-620. 
https://doi.org/10.1126/science.1204531

[16] Vocke, G. and Mir, A. (2013) U.S. Wheat Production Practices, Costs, and Yields: Variations across Regions. EIB-116, US Department of Agriculture, Economic Research Service, August 2013.

https://www.ers.usda.gov/webdocs/publications/43783/39923_eib116.pdf?v=41516

[17] Brisson, N., Gary, C., Justes, E., et al. (2003) An Overview of the Crop Model STICS. European Journal of Agronomy, 18, 309-332. https://doi.org/10.1016/S1161-0301(02)00110-7

[18] Jones, J.W., Porter, C.H., Hoogenboom, G., et al. (2003) The DSSAT Cropping System Model. European Journal of Agronomy, 18, 235-265. https://doi.org/10.1016/S1161-0301(02)00107-7

[19] Keating, B.A., Carberry, P.S., et al. (2003) An Overview of APSIM, a Model Designed for Farming Systems Simulation. European Journal of Agronomy, 18, 267-288.

[20] Stöckle, C.O., Donatelli, M. and Nelson, R. (2003) CropSyst, a Cropping Systems Simulation Model. European Journal of Agronomy, 18, 289-307.

https://doi.org/10.1016/S1161-0301(02)00109-0

[21] Zhang, X.C. (2005) Spatial Downscaling of Global Climate Model Output for Site-Specific Assessment of Crop Production and Soil Erosion. Agricultural and Forest Meteorology, 135, 215-229. https://doi.org/10.1016/j.agrformet.2005.11.016

[22] Zhang, X.C., Nearing, M.A., Gabrecht, J.D. and Steiner, J.L. (2004) Downscaling Monthly Forecasts to Simulate Impacts of Climate Change on Soil Erosion and Wheat Production. Soil Science Society of America Journal, 68, 1376-1385. https://doi.org/10.2136/sssaj2004.1376

[23] Hoogenboom, G., et al. (2015) Decision Support System for Agrotechnology Transfer (DSSAT). DSSAT Foundation, Prosser, Washington DC. http://dssat.net/

[24] Edwards, J.T., Smitha, E.L., Hunger, R.M., et al. (2011) “Duster” Wheat: A Durable, Dual-Purpose Cultivar Adapted to the Southern Great Plains of the USA. Journal of Plant Registrations, 6, 37-48. https://doi.org/10.3198/jpr2011.04.0195crc

[25] Jones, C.D., Ritchie, J.T., Kiniry, J.R., Godwin, D.C. and Otter, S.I. (1983) The CERES Wheat and Maize Models. Proceedings of the International Symposium on Minimum Data Sets for Agrotechnology Transfer, Patancheru, India, 21-26 March 1983, 95-100.

[26] Ritchie, J.T. and Otter, S. (1985) Description and Performance of CERES-Wheat: A User-Oriented Wheat Yield Model. In: Willis, W.O., Beltsville, M.D., et al., Eds., ARS Wheat Yield Project, ARS-38, Natural Technology Information Service, Springfield, Missouri, 159-175.

[27] Castañeda-Vera, A., Leffelaar, P.A., Álvaro-Fuentes, J., Cantero-Martínez, C. and Mínguez, M.I. (2015) Selecting Crop Models for Decision Making in Wheat Insurance. European Journal of Agronomy, 68, 97-116. https://doi.org/10.1016/j.eja.2015.04.008

[28] Thornton, P.E., Thornton, M.M., Mayer, B.W., Wei, Y., Devarakonda, R., Vose, R.S. and Cook, R.B. (2016) Daymet: Daily Surface Weather Data on a 1-Km Grid for North America, Version 3. ORNL DAAC, Oak Ridge, Tennessee.

[29] Brock, F.V., Crawford, K.C., Elliott, R.L., Cuperus, G.W., Stadler, S.J., Johnson, H.L. and Eilts, M.D. (1995) The Oklahoma Mesonet: A Technical Overview. Journal of Atmospheric and Oceanic Technology, 12, 5-19.

[30] Donatelli, M., Bellocchi, G. and Fontana, F. (2003) RadEst3.00: Software to Estimate 
Daily Radiation Data from Commonly Available Meteorological Variables. European Journal of Agronomy, 18, 363-367. https://doi.org/10.1016/S1161-0301(02)00130-2

[31] Kunkel, K.E., et al. (2013) Regional Climate Trends and Scenarios for the U.S. National Climate Assessment. Part 3. Climate of the Midwest U.S. NOAA Technical Report NESDIS, 142-143.

[32] Pierce, D.W., Barnett, T.P., Santer, B.D. and Gleckler, P.J. (2009) Selecting Global Climate Models for Regional Climate Change Studies. Proceedings of the National Academy of Sciences of the United States of America, 106, 8441-8446. https://doi.org/10.1073/pnas.0900094106

[33] Gleckler, P.J., Taylor, K.E. and Doutriaux, C. (2008) Performance Metrics for Climate Models. Journal of Geophysical Research: Atmospheres, 113, D06104. https://doi.org/10.1029/2007JD008972

[34] Semenov, M.A. and Stratonovitch, P. (2010) Use of Multi-Model Ensembles from Global Climate Models for Assessment of Climate Change Impacts. Climate Research, 41, 1-14. https://doi.org/10.3354/cr00836

[35] Taylor, K.E., Stouffer, R.J. and Meehl, G.A. (2012) An Overview of CMIP5 and the Experiment Design. Bulletin of the American Meteorological Society, 93, 485-498. https://doi.org/10.1175/BAMS-D-11-00094.1

[36] Estes, L.D., Bradley, B.A., Beukes, H., et al. (2013) Projected Climate Impacts to South African Maize and Wheat Production in 2055: A Comparison of Empirical and Mechanistic Modeling Approaches. Global Chang Biology, 19, 3762-3774. https://doi.org/10.1111/gcb.12325

[37] Jones, P.G. and Thornton, P.K. (2013) Generating Downscaled Weather Data from a Suite of Climate Models for Agricultural Modeling Applications. Agricultural Systems, 114, 1-5. https://doi.org/10.1016/j.agsy.2012.08.002

[38] Mathukumalli, S.R., Sengottaiyan, V., Dammu, M., et al. (2016) Prediction of Helicoverpa armigera Hubner on Pigeonpea during Future Climate Change Periods Using MarkSim Multimodel Data. Agricultural and Forest Meteorology, 228-229, 130-138. https://doi.org/10.1016/j.agrformet.2016.07.009

[39] Zhang, X.C. (2012) Cropping and Tillage Systems Effects on Soil Erosion under Climate Change in Oklahoma. Soil Science Society of America Journal, 76, 1789-1797. https://doi.org/10.2136/sssaj2012.0085

[40] Qian, B.D., De Jong, R., Huffman, T., Wang, H. and Yang, J.Y. (2016) Projecting Yield Changes of Spring Wheat under Future Climate Scenarios on the Canadian Prairies. Theoretical and Applied Climatology, 123, 651-669.

https://doi.org/10.1007/s00704-015-1378-1

[41] Smith, W.N., Desjardins, R.L., Grant, B.B., et al. (2013) Assessing the Effects of Climate Change on Crop Production and GHG Emissions in Canada. Agriculture, Ecosystems \& Environment, 179, 139-150. https://doi.org/10.1016/j.agee.2013.08.015

[42] Hoogenboom, G., Tsuji, G.Y., Pickering, N.B., Curry, R.B., Jones, J.W., Singh, U. and Godwin, D.C. (1995) Decision Support System to Study Climate Change Impacts on Crop Production. In: Rosenzweig, C., Ed., Climate Change and Agriculture: Analysis of Potential International Impacts, American Society of Agronomy, Madison, WI, 51-75.

[43] Asseng, S., Ewert, F., et al. (2013) Uncertainty in Simulating Wheat Yields under Climate Change. Nature Climate Change, 3, 827-832.

https://doi.org/10.1038/nclimate1916 
[44] Challinor, A.J., Wheeler, T.R., Craufurd, P.Q., Slingo, J.M. and Grimes, D.I.F. (2004) Design and Optimisation of a Large-Area Process-Based Model for Annual Crops. Agricultural and Forest Meteorology, 124, 99-120.

https://doi.org/10.1016/j.agrformet.2004.01.002 